\title{
Spike Architecture Traits Associated With Type II Resistance to Fusarium Head Blight in Bread Wheat
}

\section{Maria F Franco}

Unidad Integrada Balcarce and CONICET

\section{Gladys Lori}

Universidad Nacional de la Plata Facultad de Ciencias Agrarias y Forestales

\section{Maria G Cendoya}

Unidad Integrada Balcarce

\section{Maria P Alonso}

Unidad Integrada Balcarce and CONICET

Juan S Panelo

Unidad Integrada Balcarce

Ismael Malbrán

Universidad Nacional de la Plata

Nadia E Mirabella

Unidad Integrada Balcarce

Ana Clara Pontaroli ( $\square$ pontaroli.ana@inta.gob.ar)

Unidad Integrada Balcarce and CONICET https://orcid.org/0000-0002-2605-7668

\section{Research Article}

Keywords: Fusarium graminearum, Triticum aestivum L., inflorescence traits, passive resistance

Posted Date: March 30th, 2021

DOI: https://doi.org/10.21203/rs.3.rs-242486/v1

License: (c) (i) This work is licensed under a Creative Commons Attribution 4.0 International License.

Read Full License

Version of Record: A version of this preprint was published at Euphytica on November 5th, 2021. See the published version at https://doi.org/10.1007/s10681-021-02936-3. 
SPIKE ARCHITECTURE TRAITS ASOCIATED WITH TYPE II RESISTANCE TO FUSARIUM HEAD BLIGHT IN BREAD WHEAT

Franco $\mathrm{MF}^{\mathrm{ab} 1}$; Lori, $\mathrm{GA}^{\mathrm{cd}}$; Cendoya, $\mathrm{G}^{\mathrm{a}}$; Alonso, $\mathrm{MP}^{\mathrm{ab}}$; Panelo, JS ${ }^{\mathrm{ac} 2}$; Malbrán, I ${ }^{\mathrm{bd}}$; Mirabella, $\mathrm{NE}^{\mathrm{a}}$; Pontaroli, $\mathrm{AC}^{\mathrm{ab} 3}$

${ }^{\mathrm{a}}$ Unidad Integrada Balcarce (Facultad de Ciencias Agrarias, Universidad Nacional de Mar del Plata Estación Experimental Agropecuaria Balcarce, Instituto Nacional de Tecnología Agropecuaria), CC 276 (7620), Balcarce, Argentina

${ }^{\mathrm{b}}$ Consejo Nacional de Investigaciones Científicas y Técnicas (CONICET), Godoy Cruz 2290 (1425) CABA, Argentina

${ }^{\mathrm{c}}$ Comisión de Investigaciones Científicas de la Provincia de Buenos Aires (CIC), CC 276 (7620) Balcarce, Argentina

${ }^{\mathrm{d}}$ Centro de Investigaciones de Fitopatología (CIDEFI), Facultad de Ciencias Agrarias y Forestales, Universidad Nacional de La Plata, CC 31 (1900) La Plata, Buenos Aires, Argentina

ORCID: ${ }^{1}$ 0000-0001-6039-7984; ${ }^{2}$ 0000-0002-0075-0157

${ }^{3}$ Corresponding author. Ana Clara Pontaroli, CC 276 (7620) Balcarce, Argentina. Phone +54 2266 439103 ext 567/333; FAX +54 2266 439101; email pontaroli.ana@inta.gob.ar

\begin{abstract}
Fusarium head blight (FHB) remains a devastating disease in bread wheat (Triticum aestivum L.) and other small grains. Genetic resistance to FHB is a complex trait; in addition to active physiological resistance, plant developmental and morphological traits may indirectly affect disease progression and provide a passive mechanism of resistance. In this study, we investigated the relationship between FHB type II resistance and spike architecture traits in a recombinant inbred line (RIL) population of bread wheat. Disease resistance traits were FHB severity at 21 days post inoculation (dpi) and area under the disease progress curve (AUDPC). Spike architecture traits measured were rachis length, spike density, number of spikelets per spike, florets per spike and florets per spikelet.
\end{abstract}


The RIL population showed significant variation for all traits. Heritability values were moderate to high for FHB severity (0.69) and AUDPC (0.63) and high for the spike architecture traits $(0.74$ 0.92). FHB severity and AUDPC showed a moderate and significant association with the number of florets per spike ( $r=0.38$ and $r=0.31$, respectively) and with the number of florets per spikelet $(r=$ 0.28 and $r=0.27$, respectively), reflecting a greater spread of the fungus in spikes with higher floret number. These results suggest that the number of florets per spike and the number of florets per spikelet should be considered in FHB resistance breeding efforts, because selection of lines with higher number of florets could lead to a correlated selection response towards increased FHB levels under field conditions.

Key words: Fusarium graminearum, Triticum aestivum L., inflorescence traits, passive resistance.

\section{INTRODUCTION}

Fusarium head blight (FHB), also known as head scab, is one of the most devastating diseases of wheat, frequently causing epidemics in many wheat-growing areas of the world (Lori et al. 2003; Mazzilli et al. 2007). This disease is prevalent in regions with prolonged warm and humid climatic conditions in the period from flowering to the soft dough stage of kernel development (Bai and Shaner 1994; Sutton 1982).

Although many Fusarium species can cause FHB, Fusarium graminearum Schwabe is one of the main pathogens associated with the disease in many countries of the world, including Argentina (Malbrán and Lori 2014; Schroeder and Christensen 1963; Sutton 1982). The fungus invades the spikes predominantly by direct penetration and colonizes the rachis and the spikelets. In this way, FHB leads to severe losses not only in grain yield but also in quality, decreasing seed germination and flour baking properties (McMullen et al. 1997). Damaging effects are further aggravated by the accumulation of mycotoxins produced by the fungus in the grains, which render them inappropriate for human or animal consumption (Kendrick 1992). Different control strategies such as crop rotation, tillage practices and fungicide application have been proposed to reduce the impact of FHB. However, these agronomic practices have a limited success. Therefore, the employment of FHB-resistant 
cultivars is still the most reliable and consistent strategy for minimizing losses caused by the disease (CIMMYT 2019).

Resistance to FHB is a complex trait: it is quantitatively inherited, significantly affected by environmental conditions, and subjected to strong genotype-by-environment interactions (Bai and Shaner 1994). Resistance to this disease is the result of passive and active mechanisms (Mesterhazy 1995; Rudd et al. 2001). Passive resistance includes morphological and developmental traits (for example: plant height, spike architecture and flowering date) which alter conditions for initial infection and subsequent fungal growth in the spike (Buerstmayr and Buerstmayr 2015). On the other hand, active resistance mechanisms comprise biochemical pathways that produce compounds that affect the pathogen during and/or after infection (Wiese 1987). The two main types of resistance to FHB are resistance to initial infection (Type I) and resistance to spread of the pathogen within the spike after infection (Type II) (Schroeder and Christensen 1963). In this way, considering that plant architecture can play a significant role in disease resistance, establishing the relationship between FHB resistance and architectural traits affecting disease development could be an advantageous strategy for accelerating the development of resistant varieties (Zhu et al. 1999).

So far, several plant morphological and developmental traits have been investigated for their association with FHB resistance. However, most of these studies have been carried out for FHB type I resistance. Thus, resistance to initial infection has been correlated with flower opening and duration of flower opening (Pugh et al. 1933; Zhang et al. 2018), extent of anther extrusion/retention (Buerstmayr and Buerstmayr 2015; Kubo et al. 2013; Skinnes et al. 2005), plant height (Gervais et al. 2003; Steiner et al. 2004) and flowering date (Buerstmayr et al. 2012; Steiner et al. 2004), among others. However, little is known about the effect of morphological traits on type II resistance.

Since Fusarium head blight is a floral infection disease (Arthur 1891), once penetration occurs on the inner surfaces of the lemma and palea or on the upper portion of the ovary, fungal hyphae spread downwards to the rachilla and rachis node by inter- and intracellular growth. When the hyphae reach the rachis, they spread upwards and downwards the entrance point through vascular bundles in the rachis (Kang and Buchenauer 2000). Then, it may be hypothesized, for example, that wheat plants which exhibit a longer rachis or lower inflorescence compactness have a lower disease progress and 
severity by reducing the speed with which Fusarium hyphae can extend into the spike. In this way, the aim of this research was to study the relationships between FHB type II resistance and spike architecture traits, in order to enhance the current knowledge on this complex pathosystem from a breeding standpoint.

\section{MATERIALS AND METHODS}

\section{Plant material}

A biparental population of 126 recombinant inbred lines (RILs) was developed from a cross between 'Baguette 10' and 'Klein Chajá', two spring bread wheat cultivars of very different genetic background, agronomically adapted for cultivation in Argentina. This population was generated at the Instituto Nacional de Tecnología Agropecuaria (INTA) (Alonso et al. 2018; Martino et al. 2015; Mirabella et al. 2016). Both parental cultivars display medium FHB resistance level, but differ in spike architecture, as 'Baguette 10' has compact spikes whereas 'Klein Chajá' has lax spikes at maturity.

\section{Fusarium head blight resistance evaluation}

\section{Field experiments}

The RIL population, the parental cultivars and four commercial checks were tested in field experiments at the INTA Balcarce Experimental Station (37046’15', S; 58 $18^{\prime}$ '24' W; 112 m.a.s.1.), Buenos Aires province, Argentina during two consecutive years (2016 and 2017). In each crop season, two experiments were carried out, which differed in their sowing date by ca. one month; resulting in a total of four experiments (environments). Experiments were arranged as randomized complete block designs with two blocks (or replications). Sowing dates, sowing density and crop management were as described in Franco et al. (2020).

\section{Inoculation technique and disease assessment}

A macroconidial suspension of $F$. graminearum -isolate 'SP1'- was used for inoculation. This isolate was previously characterized by its aggressiveness and it was used in this study because it 
caused the highest disease severity in two consecutive field tests (Malbrán et al. 2012; Malbrán et al. 2014). The macroconidial suspension was prepared as described by Malbrán et al. (2012) and the concentration was adjusted to $\sim 100,000$ spores $\mathrm{ml}^{-1}$ using a haemocytometer.

Anthesis date, defined as the date in which $50 \%$ of the spikes of each individual plot was flowering -Zadoks growth stage 65 (Zadoks et al. 1974)-, was recorded for each genotype in all plots. Then, ten flowering spikes per plot were randomly picked and tagged with a numbered label for identification. The spikes were inoculated using the point inoculation (PI) technique as described in Franco et al. (2020).

Development of FHB symptoms was followed individually on each inoculated spike. The number of infected spikelets per spike was determined visually 12, 17, and 21 days post inoculation (dpi). FHB severity was estimated as the proportion of infected spikelets in a spike at 21 dpi (number of infected spikelets divided by the total number of spikelets per spike). The Area Under the Disease Progress Curve (AUDPC) was calculated for each spike, according to Shaner and Finney (1977) as:

$$
A U D P C=\sum_{i=1}^{n} \frac{\left(S_{i+} S_{i+1}\right)}{2} *\left(t_{i+1}-t_{i}\right)
$$

where $\mathrm{Si}=$ disease severity at the $\mathrm{i}^{\text {th }}$ observation, $\mathrm{t}_{\mathrm{i}}=$ days at the $\mathrm{i}^{\text {th }}$ observation, and $\mathrm{n}=$ total number of observations.

\section{Evaluation of spike architecture traits}

Spike architecture traits were evaluated in all RILs and the parental cultivars. Rachis length, number of spikelets per spike and spike density were determined in all inoculated spikes. Rachis length was measured as the distance in $\mathrm{cm}$ between the top and the bottom node of the rachis. Number of spikelets per spike was the total number of fertile spikelets per spike. The average number of spikelets per $\mathrm{cm}$ of rachis length was calculated and used as an estimation of spike density. Number of florets per spike was counted on 15 randomly chosen spikes per plot from the two field experiments carried out in 2016 and one field experiment in 2017. The average number of florets per spikelet was estimated as the number of florets in the spike divided by the total number of spikelets in the spike. 
Statistical analyses were performed using R software (R Core Team 2013). All the data was analyzed fitting linear mixed models with the lme function from package $n l m e$ (Pinheiro et al. 2013). Residuals were tested for normality and homoscedasticity and a log-transformation was performed for FHB severity and AUDPC to normalize residuals. Models for logarithm of FHB severity and AUDPC were fitted considering the anthesis date as a fixed factor and genotypes and genotypes $\mathrm{x}$ environment interaction as random factors according to Franco et al. (2020).

Models for spike traits were fitted considering environment and block within environment as fixed effects and genotypes and genotype $\mathrm{x}$ environment interaction as random effects:

$$
y_{i j k}=\mu+\alpha_{j}+\beta_{k(j)}+\tau_{i}+\gamma_{j(i)}+\varepsilon_{i j k}
$$

Where $y_{i j k}$ is the logarithm of the response variable on block " $k$ " of line " $i$ " in the environment " $j ", \mu$ is the mean value of the of response variable, $\alpha_{j}$ is the fixed effect of the environment " $j ", \beta_{k(j)}$ is the fixed effect of the block " $k$ " in the environment " $j ", \tau_{i}$ is the random effect of line " $i$ ", $\gamma_{j(i)}$ is the random interaction effect between line " $i$ " and environment " $j$ ", and $\varepsilon_{i j k(s)}$ is the random error of the observation on repetition " $k$ " of line " $i$ " in the environment " $j$ ".

Assumptions on this model are: $\tau_{i} \sim N\left(0 ; \sigma_{g}^{2}\right), \gamma_{j(i)} \sim N\left(0 ; \sigma_{g e}^{2}\right)$ and $\varepsilon_{i j k} \sim N\left(0 ; \sigma_{\text {res }}^{2}\right)$ all are independent of each other.

Sequential restricted maximum likelihood ratio tests were performed to determine the significances of the random effects of lines and lines by environment interactions. For all the variables, Best Linear Unbiased Predictors (BLUPs) were obtained for all RILs and parental cultivars. Variance components were estimated by the restricted maximum likelihood (REML) method (Milliken and Johnson 2001) and broad-sense heritabilities $\left(\mathrm{H}^{2}\right)$ were estimated from variance components according to Hallauer et al. (2010), as follows:

$$
H^{2}=\frac{\sigma_{g}^{2}}{\sigma_{g}^{2}+\left(\frac{\sigma_{g e}^{2}}{e}\right)+\left(\frac{\sigma_{r e s}^{2}}{r e}\right)}
$$


where $\sigma_{g}^{2}$ is the genotypic variance, $\sigma_{g e}^{2}$ is the genotype x environment interaction variance, $\sigma_{\text {res }}^{2}$ is the error variance; e is the number of environments, and $\mathrm{r}$ is the number of replications per experiment.

To determine the significance of the genetic correlation between all the evaluated traits, Pearson correlation tests were performed with the obtained BLUPs.

\section{RESULTS}

\section{FHB severity and AUDPC}

Despite the great environmental variation observed between environments as well as between inoculation dates (Fig. S1 and Fig. S2), FHB symptoms were present in all field experiments and evaluated genotypes, with an overall $70 \%$ incidence in conidia-inoculated spikes. Mean values of the parental cultivars and means, minimum and maximum scores and standard deviations of the RIL population for each experiment as well as for the overall mean across all experiments for FHB severity and AUDPC are presented in Table 1. Sequential restricted maximum likelihood ratio tests revealed highly significant variation due to genotypes for both variables $(\mathrm{p}<0.01)$ (Table 2). The RIL population showed continuous variation for these variables across the conducted experiments (Fig. 1). Averaged across experiments, FHB severity varied within the RIL population between 0.14 and 0.69 , and the AUDPC, between 91.5 and 513.2. The parental cultivars exhibited an intermediate performance, although Baguette 10 showed consistently lower disease levels than did Klein Chajá, except for Exp. 1 in 2016. For both variables, transgressive segregation (i.e., the occurrence of RILs with more extreme values than those of the parents) was observed in all experiments. 
181

Table 1 Means, minimum (Min) and maximum (Max) values and standard deviations (SD) for FHB severity and AUDPC in the Baguette $10 \times$ Klein Chajá RIL population $(\mathrm{N}=126)$ and parental cultivars, as evaluated in four field experiments carried out in Balcarce, Argentina.

\begin{tabular}{|c|c|c|c|c|c|c|c|c|}
\hline \multirow[t]{2}{*}{ Trait } & \multirow[t]{2}{*}{ Year } & \multirow[t]{2}{*}{ Experiment } & \multicolumn{2}{|c|}{$\begin{array}{l}\text { Means of parental } \\
\text { cultivars }\end{array}$} & \multicolumn{4}{|c|}{ Values for RIL population } \\
\hline & & & $\begin{array}{l}\text { Baguette } \\
10\end{array}$ & $\begin{array}{l}\text { Klein } \\
\text { Chajá }\end{array}$ & Mean & Min & $\operatorname{Max}$ & SD \\
\hline FHB & 2016 & 1 & 0.69 & 0.46 & 0.38 & 0.05 & 1 & 0.24 \\
\hline \multirow[t]{4}{*}{ Severity } & 2016 & 2 & 0.40 & 0.46 & 0.51 & 0.06 & 1 & 0.2 \\
\hline & 2017 & 1 & 0.18 & 0.44 & 0.24 & 0.05 & 0.85 & 0.15 \\
\hline & 2017 & 2 & 0.25 & 0.36 & 0.27 & 0.05 & 1 & 0.18 \\
\hline & Overall mean & & 0.38 & $\mathbf{0 . 4 3}$ & 0.34 & 0.05 & 1 & 0.23 \\
\hline \multirow[t]{5}{*}{ AUDPC } & 2016 & 1 & 544.1 & 218.9 & 274.7 & 10.3 & 1088.0 & 202.5 \\
\hline & 2016 & 2 & 350.9 & 262.7 & 368.4 & 11.0 & 924.4 & 193.8 \\
\hline & 2017 & 1 & 135.0 & 280.8 & 167.3 & 11.9 & 892.7 & 112.6 \\
\hline & 2017 & 2 & 192.6 & 259.9 & 214.4 & 8.5 & 855.1 & 128.9 \\
\hline & Overall mean & & 305.7 & 255.6 & 252.2 & 8.5 & 1088.0 & 177.0 \\
\hline
\end{tabular}

182

Table 2 Sequential restricted maximum likelihood ratio tests to determine the significances of the random effects of lines and line by environment interactions for severity and AUDPC.

185

\begin{tabular}{|c|c|c|c|c|c|c|c|c|c|}
\hline Trait & Model $^{\mathrm{a}}$ & & $\mathrm{Df}^{b}$ & $\mathrm{AIC}^{\mathrm{c}}$ & $\mathrm{BIC}^{\mathrm{d}}$ & $\log \operatorname{Lik}^{\mathrm{e}}$ & Test & L. Ratio $^{f}$ & p-value \\
\hline FHB & & 1 & 29 & 1.704 .002 & 1.843 .400 & -8.230 .008 & & & \\
\hline \multirow[t]{2}{*}{ Severity } & & 2 & 28 & 1.709 .290 & 1.843 .881 & -8.266 .449 & 1 vs. 2 & 728.811 & 0.0069 \\
\hline & & 3 & 27 & 1.816 .911 & 1.946 .696 & -8.814 .558 & 2 vs. 3 & 10.962 .179 & $<.0001$ \\
\hline \multirow[t]{3}{*}{ AUDPC } & & 1 & 29 & 1.864 .524 & 2.003 .922 & -9.032 .619 & & & \\
\hline & & 2 & 28 & 1.864 .798 & 1.999 .389 & -9.043 .989 & 1 vs. 2 & 227.400 & 0.1316 \\
\hline & & 3 & 27 & 1.933 .160 & 2.062 .945 & -9.395 .801 & 2 vs. 3 & 7.036 .224 & $<.0001$ \\
\hline
\end{tabular}

${ }^{a}$ Model 1 is the complete model. Models 2 and 3, sequentially omit the random effect of line by environment interaction and random effect of the lines.

${ }^{\mathrm{b}}$ Degrees of freedom

${ }^{c}$ Akaike information criterion

${ }^{\mathrm{d}}$ Bayesian information criterion

${ }^{\mathrm{e}}$ Log-Likelihood

${ }^{\mathrm{f}}$ Likelihood-ratio test

The mean spike architecture traits' values of the parental cultivars and means, minimum and maximum scores and standard deviations of the RIL population for each experiment as well as for the overall mean across all experiments are presented in Table 3. The RIL population showed significant variation for rachis length, spike density, spikelets per spike, florets per spike and florets per spikelet 
across all experiments (Table 4). A bell-shaped frequency distribution was observed for each of the

199 spike architecture traits evaluated in the population (Fig. 2). The parental cultivars showed 200 intermediate values for all the variables. As it was expected, 'Baguette 10' exhibited a higher spike 201 density than 'Klein Chajá', due to a higher number of spikelets in the spike and a shorter rachis. Also,

202 'Baguette 10' showed a lower number of florets per spikelet and per spike than did 'Klein Chajá'.

203 Transgressive segregation was observed in all experiments.

204

205 Table 3 Means, minimum (Min) and maximum (Max) values and standard deviations (SD) for spike 206 architecture traits in the Baguette 10 x Klein Chajá RIL population $(\mathrm{N}=126)$ and parental cultivars, 207 as evaluated in four field experiments carried out in Balcarce, Argentina.

208

\begin{tabular}{|c|c|c|c|c|c|c|c|c|}
\hline \multirow[t]{2}{*}{ Trait } & \multirow[t]{2}{*}{ Year } & \multirow[t]{2}{*}{ Experiment } & \multicolumn{2}{|c|}{$\begin{array}{l}\text { Means of parental } \\
\text { cultivars }\end{array}$} & \multicolumn{4}{|c|}{ Values for RIL population } \\
\hline & & & Baguette 10 & Klein Chajá & Mean & Min & Max & SD \\
\hline Rachis & 2016 & 1 & 8.2 & 9.7 & 8.8 & 6.3 & 12.1 & 0.9 \\
\hline \multirow[t]{4}{*}{ length } & 2016 & 2 & 8.5 & 10.4 & 9.3 & 6.5 & 12.4 & 1.0 \\
\hline & 2017 & 1 & 7.7 & 10.0 & 8.8 & 6.3 & 11.7 & 0.9 \\
\hline & 2017 & 2 & 9.0 & 9.4 & 8.5 & 6.4 & 11.3 & 0.9 \\
\hline & Overall mean & & 8.3 & 9.9 & 8.9 & 6.3 & 12.4 & 1.0 \\
\hline Spike & 2016 & 1 & 2.2 & 1.6 & 2.0 & 1.5 & 2.7 & 0.2 \\
\hline \multirow[t]{4}{*}{ density } & 2016 & 2 & 2.3 & 1.7 & 1.9 & 1.5 & 2.6 & 0.2 \\
\hline & 2017 & 1 & 2.2 & 1.6 & 1.9 & 1.4 & 2.8 & 0.2 \\
\hline & 2017 & 2 & 2.1 & 1.5 & 1.9 & 1.4 & 2.5 & 0.2 \\
\hline & Overall mean & & 2.2 & 1.6 & 1.9 & 1.4 & 2.8 & 0.2 \\
\hline Spikelets & 2016 & 1 & 18.0 & 15.3 & 17.3 & 13.2 & 20.8 & 1.4 \\
\hline \multirow[t]{4}{*}{ per spike } & 2016 & 2 & 19.0 & 17.8 & 17.7 & 14.4 & 21.0 & 1.3 \\
\hline & 2017 & 1 & 17.3 & 15.7 & 16.9 & 13.0 & 23.4 & 1.4 \\
\hline & 2017 & 2 & 18.3 & 14.2 & 16.4 & 12.4 & 20.3 & 1.4 \\
\hline & Overall mean & & 18.2 & 15.8 & 17.1 & 12.4 & 23.4 & 1.5 \\
\hline Florets & 2016 & 1 & 42.2 & 38.9 & 42.4 & 13.3 & 64.3 & 7.8 \\
\hline \multirow[t]{3}{*}{ per spike } & 2016 & 2 & 31.5 & 47.6 & 44.2 & 12.2 & 68.1 & 9 \\
\hline & 2017 & 1 & 33.3 & 40.8 & 39.3 & 26.7 & 56.7 & 5.2 \\
\hline & Overall mean & & 36.5 & 42.4 & 42.0 & 12.2 & 68.1 & 7.8 \\
\hline Florets & 2016 & 1 & 2.34 & 2.5 & 2.4 & 0.8 & 3.6 & 0.4 \\
\hline per & 2016 & 2 & 1.65 & 2.7 & 2.5 & 0.7 & 3.9 & 0.5 \\
\hline \multirow[t]{2}{*}{ spikelet } & 2017 & 1 & 1.91 & 2.6 & 2.3 & 1.5 & 3.4 & 0.4 \\
\hline & Overall mean & & 1.97 & 2.6 & 2.4 & 0.7 & 3.9 & 0.4 \\
\hline
\end{tabular}


Table 4 Sequential restricted maximum likelihood ratio tests to determine the significances of the random effects of lines and lines by environment interactions for the spike architecture traits.

\begin{tabular}{|c|c|c|c|c|c|c|c|c|}
\hline Trait & Model $^{\mathrm{a}}$ & $\mathrm{Df}^{\mathrm{b}}$ & $\mathrm{AIC}^{\mathrm{c}}$ & $\mathrm{BIC}^{\mathrm{d}}$ & $\log \operatorname{Lik}^{\mathrm{e}}$ & Test & L. Ratio ${ }^{f}$ & $p$-value \\
\hline Rachis & 1 & 11 & 2.330 .097 & 2.383 .961 & -1.154 .049 & & & \\
\hline \multirow[t]{2}{*}{ length } & 2 & 10 & 2.333.287 & 2.382.254 & -1.156 .643 & 1 vs 2 & 518.951 & 0.0227 \\
\hline & 3 & 9 & 2.634 .656 & 2.678 .726 & -1.308 .328 & 2 vs 3 & 30.336 .916 & $<.0001$ \\
\hline Spike & 1 & 11 & -12.522 .349 & -11.983 .713 & 6.371 .175 & & & \\
\hline \multirow[t]{2}{*}{ density } & 2 & 10 & -12.499 .499 & -12.009 .830 & 6.349 .750 & 1 vs 2 & 42.850 & 0.0385 \\
\hline & 3 & 9 & -6.146 .743 & -5.706 .041 & 3.163 .372 & 2 vs 3 & 6.372 .756 & $<.0001$ \\
\hline Spikelets & 1 & 11 & 3.147 .756 & 3.201 .620 & -1.562 .878 & & & \\
\hline \multirow[t]{2}{*}{ per spike } & 2 & 10 & 3.155 .215 & 3.204 .182 & -1.567 .608 & 1 vs 2 & 94.590 & 0.0021 \\
\hline & 3 & 9 & 3.486 .162 & 3.530 .232 & -1.734 .081 & 2 vs 3 & 3.329 .469 & $<.0001$ \\
\hline Florets & 1 & 9 & 4.697 .509 & 4.738 .456 & -2.339 .755 & & & \\
\hline \multirow[t]{2}{*}{ per spike } & 2 & 8 & 4.701 .134 & 4.737 .531 & -2.342 .567 & 1 vs 2 & 562.414 & 0.0177 \\
\hline & 3 & 7 & 4.844 .716 & 4.876 .564 & -2.415 .358 & 2 vs 3 & 14.558 .264 & $<.0001$ \\
\hline Florets & 1 & 9 & 6.671 .720 & 7.079 .892 & -3.245 .860 & & & \\
\hline per & 2 & 8 & 6.724 .175 & 7.086 .994 & -3.282 .087 & 1 vs 2 & 724.547 & 0.0071 \\
\hline spikelet & 3 & 7 & 8.317 .668 & 8.635 .135 & -4.088 .834 & 2 vs 3 & 16.134 .930 & $<.0001$ \\
\hline $\begin{array}{l}\text { a Model 1 } \\
\text { interaction } \\
{ }^{\mathrm{b}} \text { Degrees } \\
{ }^{\mathrm{c}} \text { Akaike in } \\
{ }^{\mathrm{d}} \text { Bayesian } \\
{ }^{\mathrm{e}} \text { Log-Like } \\
{ }^{\mathrm{f}} \text { Likelihoo }\end{array}$ & $\begin{array}{l}\text { l random } \\
\text { eedom } \\
\text { nation cri } \\
\text { rmation } \\
\text { od }\end{array}$ & $\begin{array}{l}\text { mode } \\
\text { ect of } \\
\text { ion } \\
\text { erion }\end{array}$ & $\begin{array}{l}\text { Models } 2 \text { an } \\
\text { he lines. }\end{array}$ & & & & y environn & \\
\hline
\end{tabular}


Table 5 Variance component estimates (genotypic, genotype $\mathrm{x}$ environment interaction and residual variances) and broad-sense heritability $\left(\mathrm{H}^{2}\right)$ for the analyzed traits.

230

\begin{tabular}{|c|c|c|c|c|}
\hline Trait & $\begin{array}{l}\text { Genotypic } \\
\text { variance }\left(\sigma_{g}^{2}\right)\end{array}$ & $\begin{array}{l}\text { Genotype x environment } \\
\text { interaction variance }\left(\sigma_{g e}^{2}\right)\end{array}$ & $\begin{array}{l}\text { Residual } \\
\text { variance }\left(\sigma_{\text {res }}^{2}\right)\end{array}$ & $\begin{array}{l}\text { Broad-sense } \\
\text { heritability }\left(H^{2}\right)\end{array}$ \\
\hline FHB severity $^{a}$ & 0.09 & 0.04 & 0.24 & 0.69 \\
\hline $\mathrm{AUDPC}^{\mathrm{a}}$ & 0.08 & 0.03 & 0.32 & 0.63 \\
\hline Rachis length $^{\mathrm{a}}$ & 0.33 & 0.05 & 0.41 & 0.84 \\
\hline Spike density $^{\mathrm{a}}$ & 0.02 & 0.001 & 0.01 & 0.92 \\
\hline Spikelets per spike ${ }^{a}$ & 0.81 & 0.16 & 0.91 & 0.84 \\
\hline Florets per spike ${ }^{b}$ & 19.9 & 5.28 & 31.40 & 0.74 \\
\hline Florets per spikelet ${ }^{\mathrm{a}}$ & 0.07 & 0.02 & 0.09 & 0.81 \\
\hline
\end{tabular}

$231 \quad{ }^{a}$ Data of 126 RILs, 4 environments (2 years x 2 experiments), two blocks within experiment

$232{ }^{b}$ Data of 126 RILs, 3 environments (2 experiments in 2016 and 1 experiment in 2017)

235 Correlation coefficients between BLUPs of FHB severity, AUDPC, rachis length, spike density, 236 spikelets per spike, florets per spike and florets per spikelet are shown in Table 6. The strongest 237 genetic correlation coefficient (0.94) was detected between FHB severity and AUDPC.

238 Both variables showed a moderate and significant association with the number of florets per spike $239(\mathrm{r}=0.38$ and $\mathrm{r}=0.31$, respectively $)$ and with the number of florets per spikelet $(\mathrm{r}=0.28$ and $\mathrm{r}=0.27$, 240 respectively), reflecting a greater spread of the fungus in spikes with higher floret number. Also, a 241 significant, positive correlation $(r=0.59)$ was found between the number of florets per spike and 242 number of florets per spikelet. Rachis length, number of spikelets per spike and spike density had no 243 influence on FHB severity or AUDPC. As it was expected, the number of spikelets per spike was 244 positively correlated with both rachis length $(r=0.58)$ and spike density $(r=0.27)$. 
Table 6 Genetic correlation coefficients between FHB severity, AUDPC, rachis length, spike density, spikelets per spike, florets per spike and florets per spikelet in the Baguette 10 x Klein Chajá RIL population, evaluated in four environments at Balcarce, Argentina $(\mathrm{N}=126)$.

\begin{tabular}{|c|c|c|c|c|c|c|}
\hline & FHB severity & AUDPC & $\begin{array}{l}\text { Rachis } \\
\text { length }\end{array}$ & $\begin{array}{l}\text { Spike } \\
\text { density }\end{array}$ & $\begin{array}{l}\text { Spikelets } \\
\text { per spike }\end{array}$ & $\begin{array}{l}\text { Florets } \\
\text { per spike }\end{array}$ \\
\hline AUDPC & $0.94 * * *$ & & & & & \\
\hline Rachis length & 0.12 & 0.10 & & & & \\
\hline Spike density & -0.13 & -0.13 & $-0.61 * * *$ & & & \\
\hline Spikelets per spike & 0.01 & 0.03 & $0.58^{* * *}$ & $0.27 * *$ & & \\
\hline Florets per spike & $0.38 * * *$ & $0.31 * *$ & $0.29 * * *$ & -0.08 & $0.27 *$ & \\
\hline Florets per spikelet & $0.28 * *$ & $0.27 *$ & -0.01 & $-0.19 *$ & $-0.19 *$ & $0.59 * * *$ \\
\hline
\end{tabular}

\section{DISCUSSION}

Passive resistance mechanisms act through expression of morphological and developmental features which alter conditions for initial infection and allow the plant to avoid contact with the pathogen or prevent the disease development once the contact has taken place (Mesterhazy 1995). To date, most studies dealing with the association between plant morphological/developmental traits and FHB resistance have focused on type I resistance (Gervais et al. 2003; Pugh et al. 1933; Steiner et al. 2004; Zhang et al. 2018). However, little has been investigated about the effect of passive mechanisms on type II resistance.

In a recent work, we found that the anthesis date is correlated with type II resistance and that the prevailing environmental conditions during this stage affect the F. graminearum spread within the spike (Franco et al. 2020). Thus, considering this trait allows a more precise and objective characterization of the level of FHB type II resistance. In the same way, gaining insight into the associations between type II resistance to FHB and the architecture of the spike may lead to a 
reduction of the "background noise" of traits that potentially influence the disease development, hence increasing FHB resistance through the introgression of such desirable traits.

In this study, FHB type II resistance was evaluated in a RIL population of bread wheat, developed from the cross between two cultivars with moderate level of resistance to FHB and contrasting spike architecture, after implementing a precise point inoculation technique at anthesis under field conditions. Also, several spike architectural traits which might alter fungal colonization of the spike were evaluated. The RIL population used in this study showed large genetic variation for both FHB severity and AUDPC across all experiments. A continuous distribution with transgressive segregation towards lower and higher values for the two variables was observed. The population also segregated for the spike architecture traits and showed a continuous normal frequency distribution with transgressive variation for all the evaluated attributes. This supports the quantitative inheritance nature of all the studied attributes. The high broad-sense heritability values obtained for FHB severity $\left(\mathrm{H}^{2}=\right.$ 0.69), AUDPC $\left(\mathrm{H}^{2}=0.63\right)$ and all the spike traits $\left(\mathrm{H}^{2}\right.$ between 0.74 and 0.92$)$ indicate that a large proportion of the variation among the evaluated lines was due to genetic effects, particularly considering that the experiments performed in this study spanned a wide array of environmental conditions. traits can provide a microclimate of high humidity in the spike, favoring the fungal spread and 
Spike density is a function of two traits -rachis length and number of spikelets per spike- (Faris et al. 2014). In the present study, spike density was not correlated with severity or with AUDPC. To date, the effect of spike density on FHB resistance is unclear. On the one hand, Buerstmayr et al. (2011) and Steiner et al. (2004) have found that laxer spikes were significantly associated with an increase in FHB type II resistance, arguing that genotypes with more compact spikes have a faster disease dissemination than do genotypes with lax spikes due to the microclimate conditions that are generated in the more compact spikes (Rudd et al. 2001). On the other hand, there are some reports indicating variable associations between these attributes depending on the population studied (Buerstmayr et al. 2012).

No association between rachis length and FHB type II resistance was detected in the present study. This is consistent with results reported by Somers et al. (2003) who, studying different associations between FHB and morphological and phenological variables under controlled conditions, found no correlation between spike length and FHB type II resistance. However, Buerstmayr et al. (2011) reported a negative and significant association $(r=-0.27)$ between spike length and AUDPC.

The number of spikelets on the spike was not correlated either with FHB severity or AUDPC. These results are in agreement with that reported by Buerstmayr et al. (2011), who, studying the association between different morphological characters and type II resistance to FHB in a population of Triticum macha Dek.et Men. x T. aestivum L., also found no significant association between the number of spikelets and the progression of the disease. Similarly, Liu et al. (2007) reported lack of correlation between the number of spikelets per spike and type II resistance to FHB.

It is important to highlight that while correlation coefficients between variables reported in the bibliography are generally estimated from the means of the variables studied (phenotypic correlations), in this study the correlations were calculated using the BLUPs for each variable (i.e., genetic correlations). An important property of BLUPs is the shrinkage towards the mean, which is often a desirable statistical property as it increases precision, while maximizing the correlation of true genotype values and predicted genotype values (Piepho et al. 2008).

In summary, the results shown here suggest that the number of florets per spike and the number of florets per spikelet should be considered in FHB resistance breeding efforts, because selection of lines 
with higher number of florets could lead to a correlated selection response towards increased FHB levels under field conditions.

\section{DECLARATIONS}

\section{Acknowledgments}

We thank members of the Grupo Trigo Balcarce (EEA Balcarce INTA) for their help with the experiments and technical assistance. Scholarships granted to M.F. Franco and M.P. Alonso by the Consejo Nacional de Investigaciones Científicas y Técnicas (CONICET) is acknowledged.

\section{Fundings}

This work was partially supported by INTA (PNCyO 1127044).

\section{Conflict of Interest}

The authors declare that they have no known competing financial interests or personal relationships that could have appeared to influence the work reported in this paper.

\section{Data availability}

The datasets used and/or analysed during the current study are available from the corresponding author on reasonable request.

\section{Author contributions}

MFF, ACP, GAL and IM designed the study. Field experiments were designed by MGC, ACP and MFF. Inoculum was prepared by IM and field experiments were performed by MFF, JSP, MPA, ACP and NEM. Statistical analyses were performed by MFF with the contribution of MGC; production of figures and tables was performed by MFF with the contribution of ACP and MGC. The manuscript was written by MFF with the contribution of ACP, MGC and GL. All authors read and approved the final manuscript.

\section{REFERENCES}

Alonso M, Abbate P, Mirabella N, Merlos F, Panelo J, Pontaroli A (2018) Analysis of sink/source relations in bread wheat recombinant inbred lines and commercial cultivars under a high yield potential environment European Journal of Agronomy 93:82-87. doi:10.1016/j.eja.2017.11.007 
Bai G, Shaner G (1994) Scab of wheat: prospects for control Plant Dis 78:760-766. doi:10.1094/PD-78-0760

Buerstmayr M, Buerstmayr H (2015) Comparative mapping of quantitative trait loci for Fusarium head blight resistance and anther retention in the winter wheat population Capo $\times$ Arina Theor Appl Genet 128:1519-1530. doi:10.1007/s00122-015-2527-8

Buerstmayr M, Huber K, Heckmann J, Steiner B, Nelson JC, Buerstmayr H (2012) Mapping of QTL for Fusarium head blight resistance and morphological and developmental traits in three backcross populations derived from Triticum dicoccum x Triticum durum Theor Appl Genet 125:1751-1765. doi:10.1007/s00122-012-1951-2

Buerstmayr M, Lemmens M, Steiner B, Buerstmayr H (2011) Advanced backcross QTL mapping of resistance to Fusarium head blight and plant morphological traits in a Triticum macha× T. aestivum population Theor Appl Genet 123:293. doi:10.1007/s00122-011-1584-x

CIMMYT (2019). https://www.cimmyt.org/news/food-security/. Accessed Accessed 2019 Sept 15

Faris JD, Zhang Z, Garvin DF, Xu SS (2014) Molecular and comparative mapping of genes governing spike compactness from wild emmer wheat Mol Genet Genomics 289:641-651

Franco M et al. (2020) Using anthesis date as a covariate to accurately assessing type II resistance to Fusarium head blight in field-grown bread wheat Crop Protect 142:105504. doi:10.1016/j.cropro.2020.105504

Gervais L et al. (2003) Mapping of quantitative trait loci for field resistance to Fusarium head blight in an European winter wheat Theor Appl Genet 106:961-970. doi:doi: 10.1007/s00122-002$1160-5$

Groth J, Ozmon E, Busch R (1999) Repeatability and relationship of incidence and severity measures of scab of wheat caused by Fusarium graminearum in inoculated nurseries Plant Dis $83: 1033-1038$

Hallauer AR, Carena MJ, Miranda Filho Jd (2010) Quantitative genetics in maize breeding vol 6. Springer Science \& Business Media, Iowa 
Kang Z, Buchenauer H (2000) Ultrastructural and immunocytochemical investigation of pathogen development and host responses in resistant and susceptible wheat spikes infected by Fusarium culmorum Physiol Mol Plant Pathol 57:255-268

Kendrick B (1992) Mycotoxins in food and feeds. In: Kendrick B (ed) The Fifth Kingdom.

Kubo K et al. (2013) Minor differences in anther extrusion affect resistance to Fusarium head blight in wheat. J Phytopathol 161:308-314. doi:10.1111/jph.12060

Liu S, Abate Z, Lu H, Musket T, Davis GL, McKendry A (2007) QTL associated with Fusarium head blight resistance in the soft red winter wheat Ernie Theor Appl Genet 115:417-427. doi:10.1007/s00122-007-0577-2

Lori GA, Sisterna MN, Haidukowski M, Rizzo I (2003) Fusarium graminearum and deoxynivalenol contamination in the durum wheat area of Argentina Microbiol Res 158:29-35. doi:doi: 10.1078/0944-5013-00173

Malbrán I, Lori GA (2014) Enfermedades fúngicas de la espiga y la semilla. In: Cordo CA, Sisterna MM (eds) Enfermedades del trigo: Avances científicos en la Argentina. Edulp, La Plata, Argentina, pp 59-79

Malbrán I, Mourelos C, Girotti J, Aulicino M, Balatti P, Lori G (2012) Aggressiveness variation of Fusarium graminearum isolates from Argentina following point inoculation of field grown wheat spikes Crop Protect 42:234-243. doi:doi: 10.1016/j.cropro.2012.05.025

Malbrán I, Mourelos C, Girotti J, Balatti P, Lori G (2014) Toxigenic capacity and trichothecene production by Fusarium graminearum isolates from Argentina and their relationship with aggressiveness and fungal expansion in the wheat spike Phytopathology 104:357-364. doi:doi: 10.1094/PHYTO-06-13-0172-R

Martino DL, Abbate PE, Cendoya MG, Gutheim F, Mirabella NE, Pontaroli AC (2015) Wheat spike fertility: inheritance and relationship with spike yield components in early generations Plant Breeding 134:264-270. doi:10.1111/pbr.1226 

enfermedad y posibilidades de uso de modelos de predicción para optimizar el control químico Agrociencia 11:11-21

McMullen M, Jones R, Gallenberg D (1997) Scab of wheat and barley: a re-emerging disease of devastating impact Plant Dis 81:1340-1348. doi:10.1094/PDIS.1997.81.12.1340

Mesterhazy A (1995) Types and components of resistance to Fusarium head blight of wheat Plant Breeding 114:377-386. doi:10.1111/j.1439-0523.1995.tb00816.x doi:10.1017/S0021859614001245

Milliken GA, Johnson DE (2001) Analysis of messy data, volume III: analysis of covariance. Chapman and Hall/CRC,

Mirabella N, Abbate P, Ramirez I, Pontaroli A (2016) Genetic variation for wheat spike fertility in cultivars and early breeding materials The Journal of Agricultural Science 154:13-22.

Mourelos C, Malbrán I, Balatti P, Ghiringhelli P, Lori G (2014) Gramineous and non-gramineous weed species as alternative hosts of Fusarium graminearum, causal agent of Fusarium head blight of wheat, in Argentina Crop Protect 65:100-104. doi:10.1016/j.cropro.2014.07.013

Piepho H, Möhring J, Melchinger A, Büchse A (2008) BLUP for phenotypic selection in plant breeding and variety testing Euphytica 161:209-228. doi:10.1007/s10681-007-9449-8

Pinheiro J, Bates D, DebRoy S, Sarkar D, Team RC (2013) nlme: Linear and nonlinear mixed effects models R package version 3:111

Pugh GW, Johann H, Dickson J (1933) Factors affecting infection of Wheat heads by Gibberella saubiuetii Journal of Agricultural Research 46. doi:19331101263

R Core Team (2013) R: A language and environment for statistical computing, 3.0.2 edn. R Foundation for Statistical Computing, Vienna, Austria

Rudd JC, Horsley RD, McKendry AL, Elias EM (2001) Host plant resistance genes for Fusarium Head Blight: sources, mechanisms,and utility in conventional breeding systems Crop Sci 41:620-627. doi:10.2135/cropsci2001.413620x

Schroeder H, Christensen J (1963) Factors affecting resistance of wheat to scab caused by Gibberella zeae Phytopathology 53:831-838. doi:19641100439 

mildewing resistance in Knox wheat Phytopathology 67:1051-1056

Skinnes H, Skegman K, Bjornstad A, Tarkegne Y, Maroy AGM (2005) Associations between anther extrusion and Fusarium head blight in European wheat. In: 4th Canadian Workshop on Fusarium Head Blight. Ontario, Canada, p 55

Somers DJ, Fedak G, Savard M (2003) Molecular mapping of novel genes controlling Fusarium head blight resistance and deoxynivalenol accumulation in spring wheat Genome 46:555-564. doi:10.1139/g03-033

Steiner B, Lemmens M, Griesser M, Scholz U, Schondelmaier J, Buerstmayr H (2004) Molecular mapping of resistance to Fusarium head blight in the spring wheat cultivar Frontana Theor Appl Genet 109:215-224. doi:10.1007/s00122-004-1620-1

Sutton J (1982) Epidemiology of wheat head blight and maize ear rot caused by Fusarium graminearum Canadian Journal of Plant Pathology 4:195-209. doi:doi: 10.1080/07060668209501326 Minnesota, USA

Zadoks JC, Chang TT, Konzak CF (1974) A decimal code for the growth stages of cereals Weed Res 14:415-421. doi:10.1111/j.1365-3180.1974.tb01084.x

Zhang W et al. (2018) Genetic characterization of type II Fusarium head blight resistance derived from transgressive segregation in a cross between Eastern and Western Canadian spring wheat Mol Breed 38:13

Zhu H et al. (1999) Does function follow form? Principal QTLs for Fusarium head blight (FHB) resistance are coincident with QTLs for inflorescence traits and plant height in a doubled haploid 
455

456

457

458

459

460

461

462

463
Fig. 1 Frequency distribution of (a) FHB severity and (b) Area Under the Disease Progress Curve (AUDPC) -average of four field experiments carried out in Balcarce, Argentina- in the Baguette $10 \mathrm{x}$ Klein Chajá RIL population $(\mathrm{N}=126)$. The values of the parental cultivars are indicated with arrows

Fig. 2 Frequency distribution of (a) Rachis length, (b) Spike density, (c) Spikelets per spike, (d) Florets per spike and (e) Florets per spikelet -average of four field experiments carried out in Balcarce, Argentina- in the Baguette $10 \mathrm{x}$ Klein Chajá RIL population $(\mathrm{N}=126)$. The values of the parental cultivars are indicated with arrows 


\section{Supplementary figures}

465

466 Fig. S1 Maximum, minimum and medium temperature during the anthesis period in Experiment 1 in 4672016 (a), Experiment 2 in 2016 (b), Experiment 1 in 2017 (c) and Experiment 2 in 2017 (d)

468 Fig. S2 Rainfall (bars) and relative humidity (lines) during the anthesis period in Experiment 1 in 4692016 (a), Experiment 2 in 2016 (b), Experiment 1 in 2017 (c) and Experiment 2 in 2017 (d) 
Figures
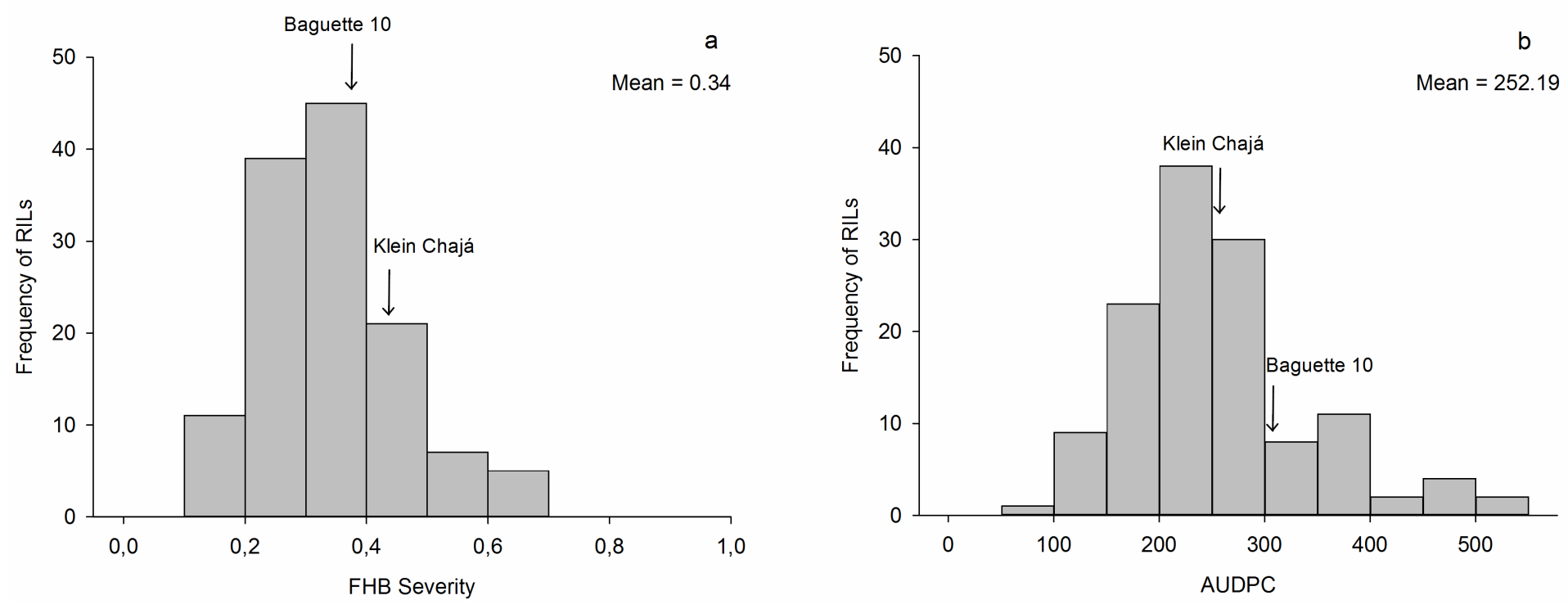

Figure 1

Frequency distribution of (a) FHB severity and (b) Area Under the Disease Progress Curve (AUDPC) average of four field experiments carried out in Balcarce, Argentina- in the Baguette 10 x Klein Chajá RIL population $(\mathrm{N}=126)$. The values of the parental cultivars are indicated with arrows 

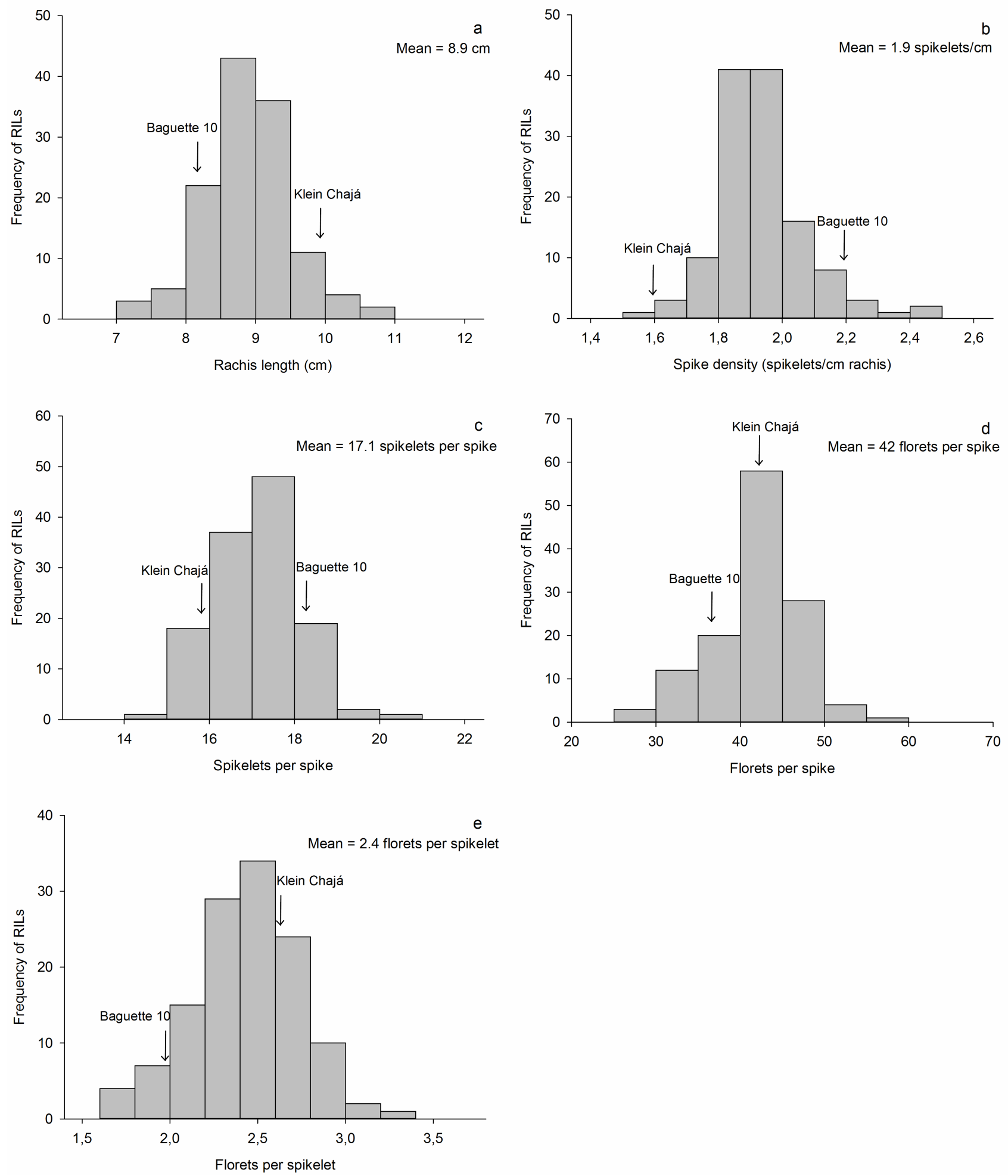

Figure 2

Frequency distribution of (a) Rachis length, (b) Spike density, (c) Spikelets per spike, (d) Florets per spike and (e) Florets per spikelet -average of four field experiments carried out in Balcarce, Argentina- in the Baguette 10 x Klein Chajá RIL population $(\mathrm{N}=126)$. The values of the parental cultivars are indicated with arrows 


\section{Supplementary Files}

This is a list of supplementary files associated with this preprint. Click to download.

- FigS1.tif

- FigS2.tif 